\title{
EL RELATO CANÓNICO DE LA TRANSICIÓN. EL USO DEL PASADO COMO GUÍA PARA EL PRESENTE
}

\author{
The Canonical Story of the Transition. The Use of the Past as a Guide to \\ the Present
}

Daniel Canales Ciudad

Universidad de Zaragoza

canalles99@gmail.com

Fecha de recepción: 28-II-2013

Fecha de aceptación: 9-III-2013

RESUMEN: La transición a la democracia se ha convertido en el más claro referente de la nueva identidad democrática espańola. En el relato oficial, los años que van de 1975 a 1981 y sus protagonistas se han elevado al panteón nacional, hasta el punto de convertirse en un período cuyas sombras son borradas intencionadamente con el fin de construir unos orígenes míticos donde fijar la nueva democracia. De esta manera, se fijó el consenso y la madurez que venían a ser los correlatos de un nuevo período de la historia de España que abandonaba la violencia y los antagonismos que habían caracterizado su pasado. Como mito, negar o poner en duda el carácter modélico de la transición se convierte en una especie de crimen contra la propia democracia. Así pues, en este artículo vamos a intentar extraer los puntos básicos de ese relato y, a partir de ellos, hacer una crítica de esa narración.

Palabras clave: transición, democracia, mito, memoria colectiva, identidad nacional.

AвSTRACт: Transition to democracy has became the clearest reference for the new Spanish democratic identity. According to the official account, the years from 1975 to 1981 and its protagonists have been reached the national pantheon even turning into a period whose shadows are intentionally deleted in order to build mythical origins where set the new democracy. Thus, consensus and maturity came to be correlates of a new period in the history of Spain, which gave up violence and antagonisms that had characterized its past. As myth, 
denying or questioning the model character of the transition has became a kind of crime against democracy itself. So in this article we are trying to draw the basics points of this story and, from them, to do an attack to that narration.

Keywords: transition, democracy, myth, collective memory, national identity.

\section{INTRODUCCIÓN. EL CUENTO DE UNA TRANSICIÓN MODÉLICA}

Las memorias más susceptibles de ser retenidas por la comunidad suelen ser tanto las heroicas como las trágicas; tanto las que evocan mitos fundacionales de los países (por ejemplo, las guerras de independencia), como los momentos de grave ruptura de la identidad nacional (por ejemplo, las guerras civiles). Unos y otros acontecimientos suelen ser objeto de intentos de elaboración mítica por parte del Estado y también por parte de los propios protagonistas $^{1}$.

No cabe duda de que el pasado es un lugar adecuado donde fijar nuestra presencia en el mundo, de ahí los esfuerzos de todo tipo de regímenes por encontrar en él sus orígenes y sus aspiraciones. Sabemos que el franquismo hundió sus raíces en el recuerdo de una guerra que legitimaba su existencia y con la que iniciaba un nuevo período de paz y prosperidad tras ańos de conflictos y degradación nacional. La democracia no iba a ser menos, y con ella quedarían superadas las rivalidades y las diferencias que habían mantenido separados a los espańoles durante ańos. Así pues, se "rompía el mito de la España diferente, de la España ingobernable, de la España anárquica ${ }^{2}$ proyectando una imagen de modernidad y convivencia democrática hacia Europa, a la que, por fin, lograba integrarse en su patrón de libertades y progreso. La transición alcanzó en los años ochenta un carácter modélico y ejemplar para otros países que podían ver en España la superación pacífica de cuarenta años de dictadura y la ruptura con su pasado más traumático ${ }^{3}$. Pero si de cara al exterior la transición había mostrado una España diferente, en el interior pasaba a convertirse en el mito fundacional de esa nueva democracia que había destejido su pasado más inmediato y sus implicaciones con la dictadura. Con todo ello se producía una redefinición del nacionalismo español que durante cuarenta años había sido dominado por la extrema derecha y que ahora pasaba a configurarse, no sin dificultades ${ }^{4}$, en

1 Paloma AGUILAR FERNÁNDEZ: Memoria y olvido de la Guerra Civil española, Madrid, Alianza, 1996, p. 356.

2 Abel HERNÁNDEZ (ed.): Fue posible la concordia. Adolfo Suárez, Madrid, Espasa, 1996, p. 159.

3 Para ver la influencia y la imagen de la transición espańola en el mundo, Bénédicte ANDRE-BAZZANA: Mitos y mentiras de la transición, El Viejo Topo, 2006, pp. 72-159.

4 Un ejemplo de la dificultad de tal fenómeno fue la instauración del 6 de diciembre, día de la Constitución, como fiesta nacional. Ver Carlos BARRERA: «El día de la Constitución y la Con- 
base a una constitución que se articulaba como el correlato oficial de la reconciliación de todos los españoles 5 . Esa reconciliación venía a superar «la dramática y calamitosa historia de España desde 1800 hasta nuestros días» ${ }^{6}$ durante la cual, la división y los maximalismos habían dominado la vida política de los españoles. La transición iniciaba, de esta manera, un nuevo período de convivencia democrática y pacífica.

Es más, «desde 1975 se produjo una especie de auto-celebración del presente» ${ }^{7}$, un año en el que se situaría el punto de partida a partir del cual toda la nación debía trabajar junta dejando a un lado los viejos fantasmas que amenazaban con abrir las brechas que habían destruido el país hacía cuarenta años. Juan Carlos Monedero invita a la reflexión cuando afirma que el relato de "la Transición era una patraña piadosa, una mentira de familia que ocultaba un pasado poco heroico y ayudaba al país a sentirse mejor de lo que era» ${ }^{8}$. Todo ese relato de la "Transición» se construyó a partir de una narración en la que los grandes hombres, al estilo de la vieja historiografía rankeana, habrían sabido conjurarse y encontrar el consenso para llevar a buen puerto aquel barco que había iniciado con la muerte de Franco un complicado trayecto hacia la democracia'. Y como espejo de lo que Espańa era, se fijó el lenguaje del consenso y la concordia dentro de un proceso por el cual la democracia estaba prácticamente asegurada gracias a la voluntad reformista de sus protagonistas, a la modernización económica y social que había vivido España desde los años 60, a la madurez del pueblo espańol y al contexto internacional que apuntaba ya al triunfo de la democracia sobre suelo peninsular. Se configuraba así una transición que había evitado los errores del pasado, e inauguraba un presente que venía a ser «el comienzo de toda una transformación de hábitos y costumbres arraigados en la vida política española durante más de un siglo de guerras civiles, pronunciamientos y represión terrorista» ${ }^{10}$.

stitución política de una memoria colectiva democrática en España», disponible en formato PDF en <http://www.ahistcon.org/docs/Santiago/pdfs/s1d.pdf $>$ (consulta realizada 28 de diciembre de 2012).

5 Para una crítica del patriotismo constitucional español y su incompatibilidad con el modelo propuesto por Habermas ver Xacobe BASTIDA FREIXEDO, «La senda constitucional, la nación española y la Constitución» en Carlos TAIBO (dir.): Nacionalismo español. Esencia, memoria e instituciones, Libros de la Catarata, 2007, pp. 113-158.

6 Pilar y Alfonso FERNÁNDEZ-MIRANDA: Lo que el rey me ha pedido. Torcuato Fernández-Miranda y la Reforma Politica, Plaza \& Janes, 1995, p. 38.

7 Josefina CUESTA: La odisea de la memoria. Historia de la memoria en España. Siglo XX, Madrid, Alianza, 2008, p. 383.

8 Juan Carlos MONEDERO: La transición contada a nuestros padres, Madrid, Los Libros de la Catarata, 2011, pp. 25-26.

9 Véase Abel HERNÁNDEZ (ed.): op. cit.

10 Estas palabras pertenecen a las resoluciones del IX Congreso del PCE de 1978 en Rafael DEL AGUILA y Ricardo MONTORO: El discurso politico de la transición española, Madrid, Siglo XXI, 1984, p. 192. 
Así pues, el propósito de este artículo es el de descubrir los elementos que han articulado todo ese relato a través de los discursos y las valoraciones del proceso transicional que aparecen en las memorias de Adolfo Suárez, Alfonso Osorio, Manuel Fraga, Martín Villa o Torcuato Fernández-Miranda. Aunque podremos acudir a otros personajes como Fernando Álvarez de Miranda, nos interesan aquéllas en particular por una cierta homogeneidad de sus relatos debido al paso dado por todos del franquismo a la democracia. Además todas ellas están publicadas en los años ochenta, años en los que se termina por definir dicho relato, a excepción del libro de Abel Hernández sobre Suárez publicado en 1996 y de las de Fernández-Miranda las cuales, ante la falta de unas memorias propias, fueron escritas en 1995 por sus dos hijos con la intención de rescatar la figura cuya actuación había sido, según ellos, ninguneada y olvidada ${ }^{11}$. Este último libro nos da la clave de las intenciones de todas estas memorias: dejar para la posteridad el testimonio de quienes «contribuyeron, desde distintas opciones, a la transformación política más completa y espectacular de nuestra historia contemporánea» ${ }^{12}$.

A partir de dichas memorias, y de cierta historiografía más cercana a la publicística de ese relato modélico que a la búsqueda del conocimiento histórico ${ }^{13}$, vamos a estudiar esa idea de transformación, de inicio de un nuevo tiempo, de ruptura con un pasado traumático que va a ser, en definitiva, el tema en el que nos vamos a centrar. En este sentido, a lo largo del artículo veremos cómo frente al pasado se contraponía un nuevo presente en el que se rompía con los vicios de aquél. De alguna manera, nuestra idea es la de mostrar la manera en que la moderación y la madurez de ese presente se colocaban frente a los extremismos del pasado. Es decir, el consenso y la concordia, representados por la Constitución y la Corona, se imponían sobre los antagonismos y la violencia. Así pues, tanto madurez como consenso se convertirían en nuevos mitos que articularían todo un relato que, como veremos en la última parte del artículo, se rescatarán en momentos de tensión e incertidumbre con unos claros fines políticos y sociales.

En relación a esto último, esta interpretación cargada de mitos todavía goza, como afirma Rubén Vega, de una notable salud gracias a su presencia en los medios de comunicación, el sistema educativo y la opinión pública ${ }^{14}$. De hecho, estamos ante un claro caso de construcción e imposición de una memoria que inserta el período de la transición en un tiempo mítico y que no deja lugar a crítica, ya que «coloca a quien la formula en una posición muy incómoda, cuando no se expone a ser señalado como militante de una

11 Pilar y Alfonso FERNÁNDEZ-MIRANDA: op. Cit., p. 247.

12 Fernando ÁLVAREZ DE MIRANDA: Del «contubernio» al consenso», Barcelona, Planeta, 1985, p. 197.

13 Un ejemplo muy claro Javier TUSELL: La Transición española a la democracia, Historia 16, 1995.

14 Rubén VEGA: «Demócratas sobrevevenidos y razón de estado. La transición desde el poder» en Historia del Presente, 12, 2008/2, II época, p. 129. 
supuesta grey satánica negacionista de la españolidad más genuina» ${ }^{15}$. Y es que la crítica a los orígenes de la democracia se convierte en una crítica a la democracia misma. Ahora bien, ciertos autores pretenden ver en la transición los problemas de la actualidad y normalmente piden una segunda transición que sea «más transparente y participativa, que acabe de una vez con los restos del franquismo que seguimos sufriendo» ${ }^{16}$. Este tipo de argumentos tienden a hacer lo mismo que quienes defienden una transición modélica, es decir, proyectan el presente en el pasado ${ }^{17}$, algo que nos lleva a reflexionar en la actualidad sobre los usos públicos de la historia. Y aunque profundizaremos al final del artículo en estas consideraciones, podemos adelantar en relación a todo esto unas palabras muy significativas de Juan Andrade Blanco:

Los maestros de la historia nos han enseńado que los relatos sobre el pasado funcionan con frecuencia como una celebración encubierta del presente y que desde ese presente celebrado se presentan como regresivas o quiméricas todas las alternativas que se opusieron a su desarrollo. Ese ha sido el caso de muchas narraciones sobre la transición, orientadas a decirnos lo felices que debíamos sentirnos por vivir en una monarquía parlamentaria y en una Europa capitalista ${ }^{18}$.

\section{LA CONSTRUCCIÓN DEL MITO. LAS LECCIONES DEL PASADO, EL CONSENSO Y LA MADUREZ}

Ese relato de la transición modélica está protagonizado por unas élites que con una voluntad de compromiso y una capacidad de maniobra ejemplares, supieron llevar a una sociedad desmovilizada y suficientemente madura a aceptar el cambio desde arriba y evitar así los desmanes de un pasado con el que se vivía "pegado a la espalda»" ${ }^{19}$ Ya hace unos ańos que Paloma Aguilar puso de manifiesto la manera en que el recuerdo de la II República y la guerra sobrevoló todo el proceso transicional y que, de algún modo, condicionó las acciones y decisiones del período ${ }^{20}$. Creyendo estar pisando sobre

15 Manuel ORTIZ HERAS: «Nuevos y viejos discursos de la transición. La nostalgia por el consenso» en Historia Contemporánea, 44 (2011), p. 340. Ver también Jordi GRACIA: "Casi cuarenta ańos», El Pais, 12 de julio de 2010.

16 Josep FONTANA: La construcció de la identitat. Reflexions sobre el passat i sobre el present, Editorial Base, 2005, p. 137.

17 Ismael SAZ: «Y la sociedad marcó el camino. O sobre el triunfo de la democracia en España (1969-1978)», en Rafael QUIROSA-CHEYROUZE Y MUÑOZ (ed.): La sociedad española en la Transición. Los movimientos sociales en el proceso democratizador, Biblioteca Nueva, 2011, p. 41.

18 Juan ANDRADE BLANCO: "Crisis y transición», en blog del diario Público el 16 de julio de 2012 <http://blogs.publico.es/dominiopublico/5502/crisis-y-transicion/> (consulta realizada el 30 de diciembre de 2012).

19 Santos JULIÁ: Elogio de historia en tiempo de memoria, Madrid, Marcial Pons, 2011, p. 24.

20 Paloma AGUILAR FERNÁNDEZ: op. cit., p. 230. 
terreno minado procuraron caminar con cuidado de no acelerar la marcha demasiado ni de poner un pie sobre aquello que podría hacer explotar todo un país, o al menos eso se decía. En un momento de crisis económica global, cambio político y de enorme movilización social los paralelismos con la experiencia republicana se hacían casi inevitables. Más si tenemos en cuenta la visión del pasado que había promovido el franquismo según la cual fue la II República lo que llevó a España a la división y, en última instancia, a la guerra civil. La experiencia democrática republicana fue olvidada y, a menudo, se tendió a verla como un período dominado por la violencia en las relaciones sociales y los extremismos en la política ${ }^{21}$. Así pues, se debía aprender de la Historia. Las palabras de Adolfo Suárez en el anuncio de su primera candidatura en TVE son muy claras al respecto:

Y porque la Historia nos enseña que debemos tomarnos muy en serio esta posibilidad; y porque estamos convencidos que existe un mayor pluralismo, me parece imprescindible presentar al pueblo español un posible factor de equilibrio, sin la amenaza permanente de la división de los espańoles en dos mitades, como si esa fuese nuestra realidad nacional ${ }^{22}$.

La guerra como una inútil matanza fratricida y la culpabilidad compartida fueron ideas que promovieron ciertos sectores del franquismo desde mediados de los ańos sesenta, unas ideas bajo las que quedaba soterrada una especie de ideosincrasia española caracterizada por su ingobernabilidad ${ }^{23}$. De alguna manera, esas ideas habían sido interiorizadas por un gran número de ciudadanos, por lo que durante el último franquismo el miedo a la vuelta a un posible enfrentamiento violento tuvo una cierta eficacia ${ }^{24}$. De hecho, ese temor también estuvo latente durante los años de la transición lo cual llevó, según Josep María Colomer, a crear unas instituciones democráticas que dieron una mayor prioridad a la estabilidad política, algo que incidió negativamente en la posterior marcha democrática del país ${ }^{25}$. Del mismo modo, algunos autores sugieren

21 Si bien se estudió la II República durante la transición, las investigaciones no superaban los límites de aquello que se sucedía en el presente. De esta manera, se comenzó a estudiar los partidos políticos, el sistema electoral y hubo una importante aportación de estudios locales. Ver Octavio RUIZ-MANJÓN: «La Segunda República española. Balance historiográfico de una experiencia democratizadora» en Ayer, 63, (2006), pp. 279-297. Será a partir de 1981, con el cincuenta aniversario de la proclamación de la República cuando verdaderamente se empiece a rescatar la experiencia democrática de los años treinta. Un claro ejemplo lo tenemos en Eduardo PRADA MANSO: «La influencia del 14 de abril de 1931 en la política actual», El País, 14 de abril de 1981. Abel HERNÁNDEZ (ed.): op. cit., pp. 78-79.

23 Esa interpretación de la guerra tuvo una importante vigencia durante la transición. Un claro ejemplo es el libro de Julián Marías, La guerra civil, ¿cómo pudo ocurrir? publicado en 1980, y que recientemente se ha reeditado en Forcola, lo que nos habla del mantenimiento, todavía hoy, de este tipo de visiones de la guerra. Ver Antonio ASTORGA: "Julián Marías: «La guerra fue consecuencia de una ingente frivolidad»» en $A B C, 30$ de abril de 2012.

24 Ferrán GÁlLEGO: El mito de la transición, Crítica, 2008, p. 162.

25 Josep M. COLOMER: «El modelo español de democratización» en Política y Gobierno, vol. VI, 
que ese miedo fue usado por las fuerzas políticas reformistas y de la oposición para contener y encauzar el cambio y encontrar, así, un espacio político propio en el nuevo sistema parlamentario ${ }^{26}$. Ahora bien, en este último caso, si bien podemos afirmar que la memoria de la guerra pudo ser instrumentalizada, debemos matizar esta consideración pues tiende a reducir la presencia y la fuerza de unas movilizaciones que ya desde los últimos ańos del franquismo reivindicaban una ruptura democrática con el régimen ${ }^{27}$.

Si como hemos visto el miedo actuó y se utilizó como un factor de resistencia al cambio, las movilizaciones sociales fueron las que impusieron el guión de fondo del período, las que hicieron inviables los intentos de reforma de Arias y Fraga y las que obligaron al gobierno de Suárez a abrir las puertas del proyecto a la oposición democrática y a la ampliación de una reforma que acabaría en ruptura con la dictadura. Autores como Pere Ysas ${ }^{28}$, Xavier Domenech ${ }^{29}$ o Ismael Saz ${ }^{30}$ han devuelto ese protagonismo del cambio a una sociedad que de alguna manera marcó el ritmo de los acontecimientos y las agendas de los diferentes proyectos políticos. Ese protagonismo debe ser reivindicado con fuerza ya que es la mejor manera de combatir esa visión modélica de la transición al introducir el conflicto en un relato que ha tendido a reducir a la sociedad a un sujeto pasivo y desmovilizado. Ahora bien, no debemos, como avisa Ferrán Gállego, destronar de la interpretación a las élites para colocar allí las movilizaciones sociales, sino que debemos integrar los dos agentes en un proceso en el que el uno al otro se influyeron mutuamente ${ }^{31}$. No obstante, en el relato oficial la realidad es bien distinta. Las movilizaciones se han tendido a ver como obstáculos y causantes del desorden que ponían en peligro la tarea de unos reformistas que condujeron con inteligencia y precaución el cambio político. La conclusión de Martín Villa, como él mismo dice,

no 1 (1999), pp. 173-185. Para un análisis más detenido de este autor ver, Íbidem: La transición a la democracia: el modelo español, Barcelona, Anagrama, 1998.

26 Enrique LARAÑA: «Los movimientos sociales y la transición a la democracia en España» en Rafael QUIROSA-CHEYROUZE Y MUNOZ (ed.): op. cit., pp. 75-76.

27 Pere YSAS: «La crisis de la dictadura franquista» en Carme MOLINERO (coord.): La transición, treinta años después, Madrid, Península, 2006, pp. 27-58.

28 Pere YSAS: «Movilización y desmovilización obrera. Del franquismo a la democracia» en Javier TEBAR: El movimiento obrero en la gran ciudad: de la movilización sociopolítica a la crisis económica, Barcelona, El Viejo Topo, 2011, pp. 273-297.

29 Xavier DOMENECH: «El cambio político (1962-1976). Materiales para una perspectiva desde abajo", en Historia del Presente, no 1 (2002), pp. 53-69.

30 Ismael SAZ: «La lucha por la libertad en España desde una perspectiva comparada (1962-1977)», en Carlos NAVAJAS ZUBELDIA y Diego ITURRIAGA BARCO (coords.): Novísima. II Congreso Internacional de Historia de Nuestro Tiempo, La Rioja, Universidad de la Rioja, 2010, pp. 84-95.

31 Ferrán GÁlLEGO: op. cit., p. 160. 
es bien sencilla: sin los reformistas del franquismo, la reforma política y el cambio no hubieran sido posibles, o al menos no se hubieran desarrollado como se desarrollaron. Es decir, legal, pacífica, serena y moderadamente.

La izquierda es la que enarbola la bandera de la democracia. Nosotros nos limitamos a traerla. Nada menos ${ }^{32}$.

Como ya hemos dicho antes, nos interesan las memorias de aquellos que, como el propio Martín Villa, actuaron en gobiernos y organizaciones franquistas. Igual que España se desligaba de su pasado inmediato para afrontar un nuevo período, los protagonistas de la reforma que venían del franquismo llevaron a cabo una adaptación de su pasado a partir del presente. La memoria permite «la posibilidad de que los acontecimientos del pasado puedan ser continuamente re-presentados, re-creados, re-interpre-

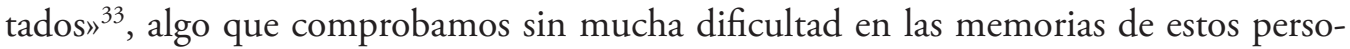
najes. Por un lado, podemos ver un ajuste del pasado al lenguaje y a las necesidades del presente. Nada más acabar la guerra Manuel Fraga recuerda que, desde un principio, se dedicó «a estudiar seriamente; comprendía que a España le esperaban horas muy difíciles, de reconstrucción y reconciliación » ${ }^{34}$. Vemos claramente como utiliza un lenguaje del momento en que escribe esas líneas para definir las motivaciones que le llevaron a la vida pública. Está integrando su pasado en una trayectoria única que se define desde el presente: la reconciliación.

Pero si para Fraga era inevitable hablar de su pasado, quizás hasta era provechoso dado que abanderó ciertos proyectos de reforma ya antes de la muerte de Franco, en otros, ese pasado es borrado intencionadamente. El ejemplo más claro lo tenemos en el libro de Abel Hernández sobre Adolfo Suárez. Como principal artífice político de la transición, había que cuidar de no manchar la trayectoria ni los discursos de Suárez. Sabemos que la selección de documentos y escritos en la investigación historiográfica es inevitable, de hecho, es algo que precisamente hemos hecho para este mismo trabajo. Ahora bien, podemos reflexionar en torno a los motivos por los que se hace una selección u otra. En este sentido, para este artículo hemos tomado las citas y los discursos que nos han parecido más adecuados para documentar con pruebas lo que estamos proponiendo. De todos modos, siendo el libro entero un elogio a la labor de Suárez en el proceso democratizador, no es extrańo que Abel Hernández omita ciertas partes de las primeras intervenciones de Suárez en las Cortes. Un claro ejemplo es el discurso del 9 de junio de 1976 antes de la aprobación en Cortes de la ley de Asociaciones Políticas. Llegado al

\footnotetext{
32 Rodolfo MARTÍN VILLA: Al servicio del Estado, Planeta, 1984, p. 50.

33 Santos JULIÁ: Historia de las dos Españas, Madrid, Taurus, 2004, p. 349.

34 Manuel FRAGA: Memoria breve de una vida pública, Barcelona, Planeta, 1980, p. 20.
} 
punto en que Suárez habla de las glorias del franquismo Abel Hernández lo resume con un «Reconoce los logros materiales del franquismo» y además, como si toda la transición hubiese sido un plan del propio Suárez continua: «y adelanta enseguida el método que luego aplicaría en la transición» ${ }^{35}$.

En relación a esto último, el libro de Abel Hernández da claras muestras de la visión teleológica de este relato de la transición. Parece como si ya desde la muerte de Franco, Suárez tuviese en mente el camino a seguir y los resultados que esperaba conseguir. Es decir, se está trazando una línea recta del presente al pasado, la democracia de la que hablaba Suárez y los reformistas de los últimos años del franquismo se presentiza y se convierte en un concepto que designa una democracia tal como la conocemos hoy en día. Nada más lejos de la realidad. Ante la crisis que amenazaba con destruir todo el edificio construido durante cerca de cuarenta años, la solución de los sectores franquistas más avanzados fue una reforma que renovase el sistema para adecuarlo a una sociedad en cambio, lo cual dotaría al régimen de una nueva legitimidad: la de la adaptación a partir del cambio ${ }^{36}$. Como dice Ferrán Gállego, el franquismo había nacido con «espíritu de permanencia» y los proyectos reformistas del primer gobierno de la monarquía no eran sino los intentos para una "conservación reformada» del propio régimen ${ }^{37}$. En este sentido, la Reforma no supuso el establecimiento de la democracia, sino el inicio de un camino hacia un sistema representativo que garantizase el control del proceso por parte de los antiguos franquistas. Nazario Aguado, dirigente entonces del Partido del Trabajo de España, corrobora esta visión cuando ante el discurso de Suárez en el que se trazaban las líneas de la Ley para la Reforma Política comentó en un tono de cierta decepción:

El presidente ha dicho exactamente lo que podíamos esperar de él. Es decir, nada que tenga que ver con la apertura de un proceso democrático. Es lo que esperábamos porque, para que en la situación del país se produjera el vuelco democrático que necesita, hubiera sido necesario, y lo sigue siendo, el establecimiento de una negociación franca y pública entre el poder de hecho y el conjunto de la oposición democrática ${ }^{38}$.

35 Abel HERNÁNDEZ (ed.): op. cit., p.36. Podemos ver la parte omitida en las memorias de Alfonso Osorio quien reproduce una parte del discurso de Suárez: «Espańa estaba sedienta de paz y este Estado se la dio. Nuestro pueblo clamaba por la justicia y este Estado alcanzó techos de justicia social que jamás se había ni siquiera soñado. España estaba necesitada de un mayor nivel de bienestar material y cultural para sobre él poder construir con carácter definitivo un amplio sistema de libertades políticas para todos. Y este Estado hizo posible que saliésemos del subdesarrollo y nos incorporáramos al grupo de países más evolucionado de Occidente. Pienso que nuestro compromiso histórico ante esta evidencia es muy sencillo: terminar la obra» Alfonso OSORIO: Trayectoria politica de un ministro de la Corona, Barcelona, Planeta, 1980, p. 80. Ver Ferrán GÁlLEGO, op. cit., pp. 29-31.

37 Íbidem, p. 314.

38 «El discurso del presidente no convenció», El País, 11 de septiembre de 1976. 
De todos modos, para el relato canónico esta Reforma fue el primer paso hacia el consenso y supuso

el punto de encuentro que permitió alumbrar una democracia con los defectos que se quiera, pero libre de un defecto inevitablemente letal: una nueva división entre vencedores y vencidos. La reforma fue, pues, cauce de reconciliación y el origen de una democracia nacida sin grandes enemigos, precisamente porque no hubo grandes derrotados ${ }^{39}$.

Esta idea de la Reforma tiende a ignorar que dicho proyecto fue algo dado por el gobierno, nunca negociado con la oposición y que en ese momento sindicatos y partidos políticos seguían en la ilegalidad. Pero si como hemos visto en las palabras de Aguado, la oposición no participó en la redacción de la Ley, la presión ciudadana y las movilizaciones obreras que ya habían imposibilitado los planes de Arias y Fraga, fueron las que forzaron a Suárez a ampliar los marcos de la reforma y a iniciar el consiguiente diálogo con una oposición que poco a poco se iba distanciando de su inicial estrategia rupturista, sin abandonarla todavía por completo. En este sentido, la huelga del 12 de noviembre de 1976 supuso el reconocimiento de socialistas y comunistas de que no contaban con la fuerza necesaria para traer por ellos mismos la democracia, pero si con la suficiente presencia en las calles como para que se tuviese en cuenta sus reivindicaciones. Se abandonaba entonces la opción de la ruptura y se crearía la Comisión de los Nueve, organismo con el que se establecería el diálogo directo entre gobierno y oposición. Algunos autores como André Bazzana hablan de que la transición fue otorgada por el gobierno y que la oposición estuvo siempre en una posición subordinada ${ }^{40}$. Esta interpretación es igual de simplista ya que no tiene en cuenta ni la fuerza ni la capacidad de las movilizaciones sociales y de la oposición para abrir el proyecto inicial de reforma hacia una verdadera democracia. Parece más adecuado hablar de que el resultado del proceso vino determinado por una correlación de fuerzas entre gobierno y oposición que se redefiniría constantemente según coyunturas como la huelga del 12 de noviembre o las elecciones de 1977.

Eso sí, que la reforma política surgiese de las filas del franquismo supuso que el cambio se hiciese "por primera vez en la historia de Espańa» «desde la legalidad» de las instituciones vigentes ${ }^{41}$, algo que evitó una experiencia como la portuguesa y la incertidumbre política en un país que tendía a perder el tiempo «en experimentos improvisados y de mal fin $»^{42}$. Como ya hemos dicho antes, la experiencia republicana marcaba

\footnotetext{
39 Pilar y Alfonso FERNÁNDEZ-MIRANDA: op. cit., p. 29.

40 Bénédicte ANDRÉ-BAZZANA: op. cit., pp. 182-195.

41 Alfonso OSORIO: op. cit., pp. 111-112.

42 Manuel FRAGA: En busca del tiempo servido, Barcelona, Planeta, 1987, p. 15.
} 
un camino que no debía repetirse. Ahora bien, había una importante diferencia con los ańos treinta, y es que

La reforma política que acabaría produciéndose durante los años 1976 y 1977 fue posible por el nivel de desarrollo económico y social alcanzado, por la madurez y la moderación del pueblo espańol, por el punto de unanimidad que para nuestras minorías terminó constituyendo el modelo de democracia occidental, por el peso y la influencia -queramos o no condicionante en un mundo homogeneizado como el actual- del contorno y por la decisión ya voluntad política del Rey. Pero el protagonismo político de esta mutación correspondió a los reformistas del franquismo ${ }^{43}$.

En esta cita, se ve claramente los principales vectores que han definido ese relato canónico de la transición a partir de la Reforma. En este sentido, fueron las transformaciones económicas y sociales producidas durante el franquismo las que facilitaron el surgimiento de una clase media de tendencias políticas moderadas que apoyase un cambio pacífico y sin traumas. De alguna manera, autores como Julio Aróstegui han planteado un esquema parecido, poniendo el acento del cambio en los ańos sesenta, esa "década prodigiosa» que produjo un ahondamiento en la "divergencia entre régimen y sociedad ${ }^{44}$. Ahora bien, sin perder de vista esa divergencia, la relación funcionalista que se da entre el aumento de los niveles de bienestar y la democratización de la cultura política de un país se ha demostrado de escaso valor para la historiografía. Esta consideración olvida que la modernización puede desarrollarse y convivir perfectamente en un sistema autoritario, tal como se ve en España desde los ańos sesenta o en la dictadura de Pinochet en la década de los ochenta. Para el caso de la transición española supone afirmar que el franquismo preparó el terreno para la democracia, un argumento que comparten gran parte de los reformistas franquistas y que pone de manifiesto su visión teleológica y simplista del proceso democratizador:

la transición política, la democracia y, por consiguiente, los cambios políticos que tuvieron lugar desde el 75 no fueron otra cosa que la culminación de otros cambios profundos y sustanciales que previamente había experimentado la sociedad española en los años que van desde 1960 hasta $1975^{45}$.

43 Rodolfo MARTÍN VILLA: op. cit., p. 49.

44 Julio ARÓSTEGUI: op. cit., p. 16. Frente a este tipo de ideas, Josep M. Colomer señala que la transición en España llegó en un momento en que la dictadura ya no podía mantener sus resultados económicos, lo que le lleva a concluir que «la liberación política y la democratización no están determinadas por las estructuras económico-sociales» sino más bien por la voluntad y las decisiones de los actores políticos del momento, tanto individuales como colectivos. Josep M. COLOMER: op. cit., p. 176.

Íbidem, p. 105. 
Por otro lado, esa relación entre modernización, moderación y democratización es la base para la construcción de un nuevo mito: el de la madurez del pueblo español, que venía a sustituir aquellos mitos de la ingobernabilidad española y rompía, de alguna manera, con las dos Españas. Estos mitos, tan manidos por el franquismo y que habían pasado a ser relatos para explicar la guerra, quedaban atados a un pasado doloroso pero que se debía tener presente. De hecho, la madurez se alcanza en la medida en que se es capaz de extraer lecciones de las experiencias y en aquellos ańos se presentaba la oportunidad de poner de manifiesto que los españoles habían aprendido la lección. Así pues, la moderación política fue el principal correlato de esa madurez:

por primera vez, en las Cortes democráticas iban a convivir los vencedores y los vencidos de la guerra civil. El pueblo español había dejado claro que estaba por la moderación ${ }^{46}$.

Como historiadores debemos rechazar esa visión de la sociedad que como todo el relato abusa del simplismo y de una autopercepción demasiado complaciente. Si hubo moderación fue más el resultado de la interiorización de los valores franquistas de conservación y de recelo a las transformaciones políticas que se relacionaban al desorden y la inseguridad, estableciendo claras referencias a la memoria de la II República y al temor de una nueva guerra. De hecho, según Ferrán Gállego serán esos valores y comportamientos los que primarán en una parte de la ciudadanía durante la transición y que supondrán el reconocimiento de que sólo se podía alcanzar la democracia a través del control institucional impulsado por los reformistas ${ }^{47}$.

Además, ese mito de la madurez del pueblo español olvida por completo ciertos aspectos que condicionaron la vida política de aquellos ańos. Se tiende a ignorar la magnitud y la importancia de las movilizaciones sociales que, como ya hemos visto, fueron determinantes a la hora de ampliar los límites de la reforma ${ }^{48}$. No obstante, en el relato que estamos estudiando, la oposición, con sus llamadas a la huelga y al desorden, suponía un obstáculo más en el proceso. De hecho, la opción rupturista fracasó ya que

46 Abel HERNÁNDEZ (ed.): op. cit., p. 82.

47 Ferrán GÁlLEGO, op. cit., pp. 159-173. Para un caso comparado entre Portugal y España de los comportamientos y actitudes de la ciudadanía durante sus respectivos procesos de cambio, Rafael DURÁN MUNOZ: «Fortaleza del Estado y acción colectiva en el cambio de régimen. España y Portugal en perspectiva comparada» en Sophie BABY, Oliver COMPAGNON y Eduardo GONZÁLEZ CALLEJA: Violencia y transiciones politicas a finales del siglo XX. Europa del Sur y América Latina, Madrid, Casa de Velázquez, 2009, pp. 157-177.

48 Ver Manuel PÉREZ LEDESMA: «Nuevos y viejos movimientos sociales», en Carmen MOLINE$\mathrm{RO}$ (coord.): op. cit., pp. 117-152. 
el único factor de poder con que jugaba la oposición era el apoyo de un pueblo consciente y movilizado, y el pueblo, más o menos libre, más o menos desinformado pero el único real, se había negado a movilizarse ${ }^{49}$.

Vemos como se presenta al pueblo como sujeto pasivo que rechaza movilizarse y si lo hace son motivaciones económicas y laborales lo que empuja las huelgas y manifestaciones. Al comentar la huelga del 12 de noviembre, Alfonso Osorio afirma que: «La convocatoria fue realizada por las centrales sindicales bajo reivindicaciones de tipo exclusivamente laboral y salarial» ${ }^{50}$. Las movilizaciones quedan de esta manera despolitizadas, es más, a menudo son tratadas de un modo condescendiente, paternalista y abocadas al fracaso:

Los trabajadores españoles ensayaban el recurso a un arma mítica, la huelga, que se les había prohibido durante muchos ańos y, antes de decidir que no era la panacea universal, necesitaban experimentarla ${ }^{51}$.

Así pues, las movilizaciones se reducían a los problemas derivados de la crisis económica. A este respecto, el horizonte lo dibujaba de nuevo la experiencia republicana. Ante los problemas de déficit de las arcas públicas, la inflación y el paro, Alfonso Osorio recuerda que había que andar con cuidado a la hora de aplicar medidas restrictivas para la economía
pues no podía olvidar, por ejemplo, las catastróficas consecuencias políticas que tuvo el plan de restricciones económicas de Chapaprieta en un momento especialmente confuso y fluido como el que precedió al 18 de julio de $1936^{52}$.

Finalmente, la solución a la que se llegó para los problemas económicos fue la firma en octubre de 1977 de los Pactos de la Moncloa, un programa económico que según Suárez «al recibir el consenso unánime de los partidos políticos, posee la virtualidad suficiente para que los españoles confíen en su eficaz aplicación» ${ }^{53}$. El consenso del que habla el entonces presidente del gobierno se ha convertido en el espíritu que dominó las actitudes de los dirigentes políticos. Al fin y al cabo, éstos habían de responder a la madurez del pueblo con el entendimiento y la concordia. Si hemos visto como en este relato la moderación se imponía a la ruptura y a las movilizaciones, el consenso se iba

\footnotetext{
49 Pilar y Alfonso FERNÁNDEZ-MIRANDA: op. cit., p. 46.

50 Alfonso OSORIO: op. cit., p. 208.

51 Rodolfo MARTÍN VILLA: op. cit., p. 17.

52 Alfonso OSORIO: op. cit., p. 141.

53 Abel HERNÁNDEZ (ed.): op. cit., p. 91.
} 
a colocar frente a los antagonismos y la violencia del pasado. Estas actitudes estarían alumbradas bajo la reconciliación nacional y la superación del pasado, un lenguaje que quedaría simbolizado por dos símbolos: la Constitución y la Monarquía.

\title{
3. LA CONSTITUCIÓN, LA MONARQUÍA Y LA RECONCILIACIÓN NACIONAL
}

Rafael Del Aguila y Ricardo Montoro hablaron ya en 1984 de ambos símbolos como "figuras sintetizadoras del consenso" ${ }^{54}$, un consenso que se establece como panacea para resolver todos los conflictos elevándolo a una categoría moral que representa el diálogo y el entendimiento. De hecho, la Constitución se creó en medio de

\begin{abstract}
un clima de amistad, por encima de discrepancias ideológicas, y de respeto mutuo, que ayudó a superar los momentos difíciles. Este ambiente de confianza y de amistad entre la clase política -tan distinta y tan distante- fue uno de los elementos que más contribuyó a llevar a cabo la reforma ejemplar de toda la transición democrática en España. En gran medida fue propiciado por el estilo personal y el afán de concordia de Adolfo Suárez ${ }^{55}$.
\end{abstract}

Vemos como, en este momento, se reivindica la figura de Adolfo Suárez, sobre quien cae el logro de haber conseguido la concordia entre las partes que antes eran antagónicas. A Suárez lo caracterizaba «el afán de concordia», el «diálogo», la «aceptación de la crítica» y el «respeto al adversario político ${ }^{56}$. Él fue quien inició el diálogo con la oposición y quien en última instancia legalizó, en una brillante operación política, el PCE. Esta interpretación se aleja por completo de la realidad. Afirmar que ambas decisiones fue el fruto de la voluntad democratizadora del gobierno es simplificar la cuestión al no tener en cuenta las coyunturas en las que se realizan. En este sentido, este relato no tiene en cuenta que ese diálogo con la oposición fue el fruto de una remodelación del reformismo llevada a cabo por Suárez tras ver que sin la oposición la reforma no podría triunfar, como había quedado de manifiesto en los intentos aperturistas de Fraga. Esa visión también se desprende, como ya hemos visto, de la presión ejercida por los movimientos sociales para que se abriesen los canales para la negociación con la oposición. En cuanto a la legalización del PCE, la presión ciudadana y la actitud del partido representada en la manifestación celebrada por el funeral de los abogados de Atocha, fueron claves para hacer entender al gobierno que no se podía prescindir de los comunistas si se quería «dar la mayor credibilidad democrática a las elecciones» ${ }^{57}$.

\footnotetext{
54 Rafael DEL ÁGUILA y Ricardo MONTORO: op. cit.

55 Abel HERNÁNDEZ (ed.): op. cit., p. 107.

56 Íbidem, p. 22.

57 Alfonso OSORIO: op. cit., p. 289. Aun así seguía habiendo partidos ilegalizados, concretamente
} 


\section{Por otro lado, la Constitución venía a expresar}

la convicción de que no hay dos Españas irreconciliables y en permanente confrontación. Creo que es el triunfo de la voluntad común de alcanzar una razonable, ordenada y pacífica convivencia de todos los españoles [...]

podemos alegrarnos como vencedores; como vencedores, no en una contienda concreta, sino pienso que en la mejor y más noble de las batallas: la batalla contra el miedo, contra el desánimo secular, contra la violencia y contra nuestras propias pasiones mantenidas ${ }^{58}$.

Así pues, frente a la violencia y los maximalismos del pasado, la nueva Constitución representaba en su totalidad la reconciliación de todos los espańoles y la definitiva superación del pasado. En su elaboración, la clave fue el consenso en el que todos renunciaron a las rivalidades para llegar a un acuerdo general que venía a construir una nueva legalidad. No obstante, hubo puntos como el de las autonomías en los que el entendimiento fue más complicado y se hizo necesario esperar unos años hasta su resolución en 1981 cuando se firmaron los Acuerdos Autonómicos entre UCD Y PSOE, tras la retirada de AP y PCE por sus desavenencias con el plan final ${ }^{59}$.

Pese a que, como hemos visto, hubo claras muestras de falta de consenso en determinados aspectos, en el relato canónico éste se ha convertido en la herramienta para el entendimiento y en el espíritu que presidió todo el proceso. Tomar el consenso como algo natural al proceso supone de nuevo abusar del lenguaje fácil, pero también conlleva la identificación de la parte con el todo. Por supuesto hubo consenso pero no fue ni mucho menos algo connatural a los dirigentes políticos, fue más bien el resultado de la correlación de fuerzas entre gobierno y oposición y que duró, podemos decir, desde finales de 1976 con el inicio de las negociaciones con la Comisión de los Nueve hasta la redacción de la Constitución. En octubre de 1978, una vez redactada la Constitución, Alfonso Guerra declaraba: «Tras la Constitución termina el consenso y comienza la oposición» ${ }^{60}$.

los que mantenían su ideario republicano intacto. No faltaron quejas al respecto en la época, una de ellas la podemos a través del entonces presidente de Acción Republicana Democrática Española, en Emilio TORRES GALLEGO: «Los republicanos, las autonomías y el terrorismo», El País, 22 de agosto de 1978.

58 Discurso de Aldofo Suárez en el Congreso de los Diputados el 31 de octubre de 1978. Abel HERNÁNDEZ: op. cit., p. 135.

59 Ver Alejandro QUIROGA FERNÁNDE DE SOTO: «Traiciones, solidaridades y pactos. La izquierda y la idea de España durante la transición» en Manuel ORTIZ HERAS (coord.): Culturas políticas del nacionalismo español. Del franquismo a la transición, Los Libros de la Catarata, 2009, pp. 73-100.

60 Manuel FRAGA: op. cit., p.132. Ver «Carrillo anuncia el fin del consenso e insiste en un Gobierno de concentración», El País, 3 de marzo de 1979 o «Felipe González sorprendió a la Cámara con el anuncio de un voto de censura», El País, 22 de mayo de 1980. 
La Constitución se convertía así en el nuevo fundamento de la nación española, lo cual suponía una recomposición de su legitimidad tras cuarenta años de dictadura y una definitiva integración en la Europa democrática ${ }^{61}$. Además rubricaba oficialmente el comienzo de un nuevo período bajo la idea de la reconciliación nacional:

\begin{abstract}
Nuestra Historia nos enseña la trágica lección de la ineficacia de unas Constituciones que han sido expresión solamente de una parte de las fuerzas políticas de la nación española. Esa lección la hemos aprendido y por ello todos nos sentimos comprometidos con una Constitución que valga para todos ${ }^{62}$.
\end{abstract}

Vemos con claridad la voluntad para la superación del pasado, la cual tuvo otro de sus principales correlatos en el decreto de amnistía del 14 de octubre de 1977. Mucha tinta se ha vertido en torno a las consecuencias de la amnistía, al olvido del pasado y a la falta de una justicia que condenase a los responsables de la dictadura. El debate es largo y no vamos a entrar en él. Solamente diremos que esa amnistía mantenía la misma lógica que presidió toda la transición: la de no reavivar odios ni diferencias y la de romper con el pasado. Quizás sea la ley que mejor represente esa ruptura, algo que para entonces se pensaba era lo adecuado pues

La España democrática debe, desde ahora, mirar hacia adelante, olvidar las responsabilidades y los hechos de la guerra civil, hacer abstracción de los cuarenta años de dictadura. La mirada hacia el pasado sólo debe tener como propósito la reflexión sobre las causas de la catástrofe y la forma de impedir su repetición. Un pueblo ni puede ni debe carecer de memoria histórica; pero ésta debe servirle para alimentar proyectos pacíficos de convivencia hacia el futuro y no para nutrir rencores hacia el pasado ${ }^{63}$.

Si amnistía ${ }^{64}$ y Constitución suponían el inicio de un nuevo tiempo, la Monarquía pese a que era una herencia directa del franquismo se elevó a esa misma categoría. No faltan quienes han repetido hasta la saciedad aquella cita de Areilza que definió al monarca como el «motor del cambio»" ${ }^{65}$, una idea que aún hoy goza de una gran popularidad. Una encuesta realizada en el año 2000 por el CIS demuestra la idea muy generalizada entre la sociedad de que la figura que más contribuyó al cambio en aquellos años fue la del

$\overline{61}$ Ver Xosé Manoel NÚNEEZ SEIXAS: «Conservadores y patriotas: el nacionalismo de la derecha española ante el siglo XXI» en Carlos TAIBO (dir.): op. cit., pp. 159-192.

62 Abel HERNÁNDEZ (ed.): op. cit., p. 113.

63 «Amnistía al fin», El Pais, 15 de octubre de 1977.

64 Para ver todas las leyes de amnistía y de reparación desde el primer indulto del rey hasta 1990, Josefina CUESTA: op. cit., pp. 393-401.

65 Charles T. POWELL, El piloto del cambio. El Rey, la monarquía y la transición a la democracia, Barcelona, Planeta, 1991. 
Rey ${ }^{66}$. Esta opinión es prácticamente unánime en las memorias que hemos trabajado. Fernández de Miranda la valora así:

Nadie ignora el papel trascendental que ha jugado la Corona, cumpliendo y haciendo cumplir la Constitución; el acatamiento de las restantes instituciones del Estado y la dinámica de los partidos que son -en alguna medida- fiel reflejo de las constantes mutaciones de una sociedad viva, plural y libre ${ }^{67}$.

Igual que en el caso de Suárez, la voluntad democratizadora de Juan Carlos queda clara ya desde que alcanza la Jefatura del Estado. Es más, «Don Juan Carlos sabía desde 1969 lo que debería hacer para establecer la Monarquía de todos, la Monarquía democrática» ${ }^{68}$. Estas palabras tienen una clara intención: la construcción de una nueva legitimidad que sustituyese la que heredaba del franquismo. No se podía borrar su presencia durante la dictadura, pero sí, como hemos visto en el caso de Manuel Fraga, reinterpretar su pasado y hacerlo asequible al presente. En su laudatoria biografía, Javier Tusell afirma que

Como le sucedió a la derecha y a la izquierda, también la Monarquía se fue convirtiendo en demócrata con el trascurso del tiempo. Así se hizo, siguiendo un ritmo histórico que tuvo que ver con el de la propia sociedad y con la evolución de los acontecimientos políticos, aunque en general se puede decir que supo adelantarse a la primera y a los segundos ${ }^{69}$.

Teniendo en cuenta estas consideraciones acerca de la monarquía no resulta extrańo que en el relato canónico su coronación signifique el momento fundacional de la democracia, lo que supone en última instancia la identificación de los sectores reformistas provenientes del franquismo con el proyecto monárquico, el cual se identificaría posteriormente con el proyecto democratizador. Así pues, podemos afirmar, como hace Rubén Vega, que la monarquía fue el «salvoconducto» que permitió a quienes venían del franquismo transitar hacia la democracia sin que tuviesen que aclarar sus orígenes ${ }^{70}$.

Lo que si es cierto, es que si el consenso había acabado con la aprobación de la Constitución, éste volvió encarnado en la figura del rey tras el golpe de estado del 23

66 "25 años después», CIS, estudio no 2401, diciembre del 2000. De todos modos, cabe decir que si el Rey es la mejor valorada le siguen muy de cerca las movilizaciones ciudadanas en general y en el movimiento obrero en particular.

67 Fernando ÁLVAREZ DE MIRANDA: op. cit., p. 197.

68 Pilar y Alfonso FERNÁNDEZ-MIRANDA: op. cit., p. 50.

69 Javier TUSELL: Juan Carlos I. La restauración de la Monarquía, Madrid, Temas de Hoy, 1995, p. 657.

70 Rubén VEGA: op. cit., p.135. Ver también Ferrán GÁLLEGO: op. cit., pp. 210-211. 
de febrero de 1981, quien vestido de militar se dirigió a toda la nación en uno de sus momentos más memorables de cara a la opinión pública. Ese fue el momento en que se unió democracia y monarquía:

La defensa de la Constitución y de la legalidad vigente ha tenido en el Rey su más resuelto y admirable combatiente. [...]

don Juan Carlos asumió la responsabilidad de la situación y encomendó a los secretarios y subsecretarios no aprehendidos por los secuestradores el ejercicio del poder civil. La actitud del Jefe del Estado en las tensas horas de ayer es símbolo de la legitimidad constitucional y democrática ${ }^{71}$.

En ese ya mítico discurso televisado la monarquia terminaba de identificarse con la democracia. El rey había salvado la Constitución y consolidado la transición a la democracia. Desde ese momento, su figura se uniría a la de la Constitución como los guardianes del orden, pasando ambos a simbolizar mejor que ningún otro momento o personaje la reconciliación de todos los españoles. En este sentido, hemos visto como el pasado fue un horizonte que evitar, un paisaje de ruinas que a menudo se rentabilizó para garantizar el orden y la moderación durante el proceso. De una manera u otra, el pasado sirvió de aprendizaje. El relato canónico destaca, como hemos visto, ese aspecto de inicio, una especie de año cero desde el que comenzar una nueva España. Durante los ańos ochenta se terminó de articular todo ese relato que pasaría a ocupar en el imaginario colectivo uno de los momentos más esplendorosos de la historia y el origen de una nueva identidad democrática basada en la madurez, la moderación y el consenso.

\section{LA INDUSTRIA DE LA TRANSICIÓN}

Hemos ido viendo de qué manera se construyó un relato de la transición que servía para afianzar la nueva Espańa en un origen común a todos los espańoles, en unas instituciones garantes del orden democrático y de unos determinados valores y comportamientos. En el año 2000, en el veinticinco aniversario de la muerte de Franco, Julio Aróstegui se preguntaba: «¿Es la transición democrática el gran suceso español del siglo $X X ?{ }^{72}$. Ante una pregunta parecida planteada el mismo ańo, un 88,6\% de los españoles declararon que la manera en que se llevó a cabo la transición constituyó un motivo de orgullo $^{73}$.

\footnotetext{
71 «Con la Constitución», El Pais, 24 de febrero de 1981.

72 Julio ARÓSTEGUI: op. cit., p. 85.

73 «25 años después», CIS, estudio n 2401, diciembre del 2000
} 
Está claro pues que la transición se había convertido en un referente para la identidad nacional de muchos españoles. Tanto es así que en situaciones de crisis se ha rescatado aquel pasado como el plano al que debemos mirar para hacer frente a las incertidumbres del presente, haciendo especial hincapié en la determinación y responsabilidad de un pueblo que demostró su madurez y responsabilidad a la hora de afrontar aquella difícil situación de cambio. Esto lo podemos ver ya en 1986 cuando el gobierno socialista se enfrenta a uno de sus mayores retos: la entrada de España en la OTAN. Según Juan Marichal la convocatoria del referéndum se presenta como la vara que iba a medir el verdadero nivel de compromiso de los espańoles con los valores democráticos encarnados por el mundo occidental. El autor llega a afirmar: "Que España pertenezca a la Alianza Atlántica es así el lógico corolario de los principios de racionalidad política que ha guiado la restauración de las instituciones democráticas. Un voto afirmativo sería, por tanto, un voto por Europa y la civilización democrática.». Del mismo modo, ante la crispación política de aquel momento, el escritor advierte que «lo que se ventila el 12 de marzo próximo para el futuro de Espańa exige que la concordia presida nuevamente la conducta de la clase política y la de los ciudadanos» ${ }^{74}$. Vemos como ya en aquellos años se rescatan los valores representados por la transición para afirmar el definitivo acercamiento al Europa y el mundo occidental concluyendo la tarea iniciada en 1975.

Pero sí vemos como apenas diez años después de que comenzase el proceso democratizador ya se utiliza la transición como espejo donde España ha de mirarse, a día de hoy el uso que se hace de aquel período es abusivo y hasta escandaloso. Ya sea en forma de declaraciones públicas en los medios de comunicación, en la página oficial de la Corona o en coloquios como el organizado por la Universidad Internacional Menéndez Pelayo en julio de 2011, «Actualidad política de los valores de la Transición Democrática» ${ }^{75}$, los valores de la transición son apuntados como los patrones que se han de seguir para afrontar los problemas que padece la sociedad hoy en día. Así pues se reivindica ese supuesto espíritu de la transición (el consenso) para la actual coyuntura política ${ }^{76}$ y se apela sin mayores reparos a «la madurez, el equilibrio y la sensatez del pueblo español» ${ }^{77}$ para aceptar los recortes contra el Estado de bienestar.

74 Juan MARICHAL: «Apelación a la concordia», El Pais, 3 de marzo de 1986.

75 <http://www.uimp.es/blogs/prensa/2011/07/26/protagonistas-de-la-transicion-reivindican-el-valor-del-consenso-y-reclaman-un-pacto-de-estado-para-hacer-frente-a-la-crisis/> (consulta realizada el 18 de diciembre de 2012).

76 «...hemos de recuperar y reforzar los valores que han destacado en las mejores etapas de nuestra compleja historia y que brillaron en particular en nuestra Transición Democrática: el trabajo, el esfuerzo, el mérito, la generosidad, el diálogo, el imperativo ético, el sacrificio de los intereses particulares en aras del interés general, la renuncia a la verdad en exclusiva». "Carta de S.M. el Rey Don Juan Carlos», 18 de septiembre de 2012. En <http://www.casareal.es/ES/FamiliaReal/rey/ Paginas/rey_cartas_detalle.aspx?data=51> (consulta realizada el 21 de diciembre de 2012).

77 «Rajoy sugiere otro recorte durísimo y apela a la sensatez de los españoles», El País, 23 de febrero de 2012. 
Así pues, se rescata aquella época en base a una nostalgia por el consenso, el entendimiento y la moderación. Esa nostalgia se articula en torno a una memoria construida a partir de ese relato canónico que, como hemos ido viendo, poco tiene que ver con lo que realmente pasó. Hoy en día la utilización de esa memoria tiene unos claros fines políticos y es que recurrir a esa madurez o a ese consenso significa apelar a un determinado tipo de comportamientos. Se rescata una democracia en la que la ciudadanía dejó a un lado las movilizaciones para conseguir el resultado deseado, la que se construyó en salones y reuniones privadas por prohombres representantes del entendimiento y la concordia, aquella democracia que destejió cuarenta ańos de dictadura y que supo afrontar el presente con la vista puesta en el futuro. De alguna manera, trayendo a la memoria esa transición parece estar pidiéndose lo mismo que para entonces: que la ciudadanía deje a un lado las protestas, acepte con madurez la situación y deje trabajar a quienes se han de encargar de sacar el país de la actual situación. 